\title{
Corrigendum: Amplification of Arctic warming by past air pollution reductions in Europe
}

J. C. Acosta Navarro, V. Varma, I. Riipinen, Ø. Seland, A. Kirkevåg, H. Struthers, T. Iversen, H.-C. Hansson and A. M. L. Ekman Nature Geoscience 9, 277-281 (2016); published online 14 March 2016; corrected after print 5 May 2016.

In the version of the Letter originally published, the following reference was mistakenly omitted:

27. Yang, Q., Bitz, C. M. \& Doherty, S. J. Offsetting effects of aerosols on Arctic and global climate in the late 20th century. Atmos. Chem. Phys. 14, 3969-3975 (2014).

This should have been cited with ref. 25 at the end of the sentence beginning 'Over the past 100 years.... The original refs $27-31$ have been renumbered accordingly. This has been corrected in the online versions of the Letter. 